\title{
Changes in air temperature over China in response to the recent global warming hiatus
}

\author{
DU Qinqin, "ZHANG Mingjun, WANG Shengjie, CHE Cunwei, MA Rong, \\ MA Zhuanzhuan \\ College of Geography and Environmental Science, Northwest Normal University, Lanzhou 730070, China
}

\begin{abstract}
The 1998-2012 global warming hiatus has aroused great public interest over the past several years. Based on the air temperature measurements from 622 meteorological stations in China, the temperature response to the global warming hiatus was analyzed at national and regional scales. We found that air temperature changed $-0.221^{\circ} \mathrm{C} / 10 \mathrm{a}$ during 1998-2012, which was lower than the long-term trend for $1960-1998$ by $0.427^{\circ} \mathrm{C} / 10 \mathrm{a}$. Therefore, the warming hiatus in China was more pronounced than the global mean. Winter played a dominant role in the nationwide warming hiatus, contributing $74.13 \%$, while summer contributed the least among the four seasons. Furthermore, the warming hiatus was spatial heterogeneous across different climate conditions in China. Comparing the three geographic zones, the monsoon region of eastern China, arid region of northwestern China, and high frigid region of the Tibetan Plateau, there was significant cooling in eastern and northwestern China. In eastern China, which contributed $53.79 \%$, the trend magnitudes were $0.896{ }^{\circ} \mathrm{C} / 10 \mathrm{a}$ in winter and $0.134^{\circ} \mathrm{C} / 10 \mathrm{a}$ in summer. In the Tibetan Plateau, air temperature increased by $0.204^{\circ} \mathrm{C} / 10 \mathrm{a}$, indicating a lack of a significant warming hiatus. More broadly, the warming hiatus in China may have been associated with the negative phase of PDO and reduction in sunspot numbers and total solar radiation. Finally, although a warming hiatus occurred in China from 1998 to 2012, air temperature rapidly increased after 2012 and will likely to continuously warm in the next few years.
\end{abstract}

Keywords: global warming hiatus; three geographic zones; temperature; China

\section{Introduction}

The Fifth Assessment Report of the Intergovernmental Panel on Climate Change (IPCC) noted that global average surface temperatures increased by $0.89^{\circ} \mathrm{C}\left(0.69-1.08^{\circ} \mathrm{C}\right)$ between 1901 and 2012, and almost all areas experienced significant warming during this period. Climate warming is one of the most important factors affecting natural ecosystems and

Received: 2018-10-08 Accepted: 2018-12-18

Foundation: National Basic Research Program of China (973 Program), No.2013CBA01801; Promotion Project for Young Teachers in Northwest Normal University, No.NWNU-LKQN-15-8

Author: Du Qinqin (1994-), Master Candidate, specialized in global change and sustainable development. E-mail: geoduqin@163.com

"Corresponding author: Zhang Mingjun (1974-), Professor, E-mail: mjzhang2004@163.com 
socio-economic systems (Jevrejeva et al., 2010; Qin et al., 2014; Zhao et al., 2016), such as sea-level rise; ocean acidification; cryosphere retreat; hydrologic cycle disruptions, including water shortages; higher frequency of extreme events, and biodiversity impairment. However, Carter (2006) of James Cook University discovered a stagnation in global warming, termed a global warming hiatus, in 2006, which has caused a fierce debate on its existence and formation (Kerr et al., 2009; Knight et al., 2009; Roberts et al., 2015; Huang et al., 2017).

Knight et al. (2009) and Kerr et al. (2009) contrasted global surface temperature changes in 1998-2012 with earlier stages based on global measured temperature data and reanalysis data, which confirming the warming hiatus. The IPCC's Fifth Assessment Report also clearly stated that the global warming trend slowed significantly in the period of 1998-2012 compared with the previous 30-60 years, which was about $1 / 3-1 / 2$ of the warming range from 1951 to 2012. However, some scholars had objections to this analysis (Cowtan et al., 2014; Karl et al., 2015; Huang et al., 2017). Karl et al. (2015) proposed that the global warming hiatus from 1998 to 2012 was caused by data issues, and that global mean surface temperature changes obtained from the revised temperature data did not show a warming hiatus. After the data calibration, the difference in temperature trends between 1951-2012 and 1998-2012 significantly decreased, and the temperature trends for 2000-2014 and 1950-1999 became very close, especially in the marine area. Huang et al. (2017) found that the Arctic region had been warming significantly in recent years, which was about six times the global warming rate since 2000. Nevertheless, previous calculations of global mean surface temperature did not take into account Arctic region changes, and the warming hiatus did not occur in reconstructions of Arctic temperature. Despite the small fluctuations in global cooling or warming, the overall warming trend in the past 100 years remains beyond doubt (Su et al., 2016). However, a warming hiatus around the world for 1998-2012 should be fully demonstrated and confirmed.

Most current studies on global warming and the warming hiatus are based on reanalysis data, which is conducive to large-scale research; however, the accuracy is not as good as that of measured data. This difference may explain why most climate models having difficulty simulating global warming and the warming hiatus (Karl et al., 2015). Furthermore, temperature changes are spatial heterogeneous across different climate conditions. Given these limitations, temperature changes across China in response to the global warming hiatus were analyzed using measured temperature data, linear trends, and the Morlet wavelet. Due to the vast territory of China, the regional natural geographical environment is complex and diverse, and there are significant differences in the nature of the underlying surface (Figure 1). Therefore, changes in the temperature response to the hiatus were analyzed on a regional scale in this study. According to comprehensive geographical divisions in China (Zhao et al., 1983), the whole country can be divided into three geographic zones based on topographic contours, tectonic movement, soil vegetation and external forces: the monsoon region of eastern China, arid region of northwestern China, and high frigid region of the Tibetan Plateau.

This study provides evidence for the global warming hiatus, and it has important scientific significance for understanding climate warming under different underlying conditions. Air temperature is a significant factor affecting the biosphere and human activities. Quanti- 
tative analysis of air temperature changes is also significant for guiding human society and living practices (Vinnikov et al., 1990).

\section{Data and methods}

\subsection{Data sources}

The monthly average air temperature dataset used in this study was obtained from the China Meteorological Data Network (http://data.cma.cn). A total of 622 stations with continuous meteorological observation records from 1960 to 2016 were selected, although there are data shortages in Hong Kong, Macao and Taiwan. Most meteorological stations are national reference climatological stations and base stations, and a few are general stations (Figure 1). For a few stations missing in individual years, a linear regression was used to interpolate between them to ensure the integrity and continuity of temperature data. In addition, the Pacific Decadal Oscillation (PDO) index was acquired as a time series for 1900-2016 from the website http://research.jisao.washington.edu/pdo/. Sunspot data was obtained from the National Oceanic and Atmospheric Administration (http://www.noaa.gov/), as a time series for 1700-2016. Total solar radiation data (historical reconfiguration data) were obtained from the LASP/LISIRD website (http://lasp.colorado.edu/lisird/tsi/historical_tsi.html) as a time series for 1610-2016.

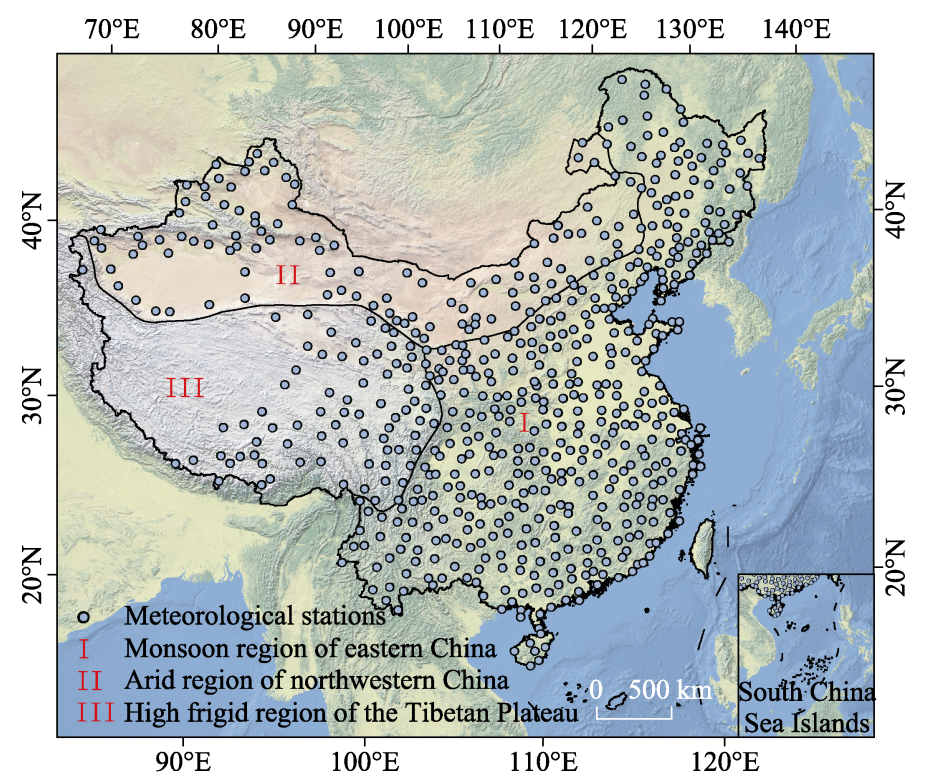

Figure 1 Location of meteorological stations and divisions in China

\subsection{Methods}

2.2.1 Average air temperature time series nationwide and for three geographic zones in China

To establish average air temperature time series nationwide and for three geographic zones in China, the method proposed by Jones (1996) was adopted. (1) According to the monthly temperature data, the annual and seasonal mean temperature series for each meteorological 
station were calculated. The four seasons were divided as follows: spring from March to May, summer from June to August, autumn from September to November, and winter from December to February of the next year. (2) The temperature anomaly for each meteorological station was calculated based on the standard period from 1971 to 2000. (3) The whole country was divided into $2^{\circ} \times 2^{\circ}$ grids by latitude and longitude, and the temperature anomalies for all stations in each grid were averaged to obtain the temperature anomaly of each grid. (4) The weighted averages of all grid temperature anomalies were obtained by the area of the grid; the formula for calculating the weighted average of all grid areas is as follows:

$$
Y_{k}=\frac{\sum_{i=1}^{m}\left(\cos \theta_{i}\right) \times Y_{i k}}{\sum_{i=1}^{m} \cos \theta_{i}}
$$

where $Y_{k}$ is the regional average of the $k$-th year, $i=1,2,3, \ldots, \mathrm{m}$ ( $\mathrm{m}$ is the number of grids), $Y_{i k}$ is the average of the $k$-th year in the $i$-th grid, and $\theta_{i}$ is the $i$-th latitude of grid centers.

2.2.2 Method for calculating the seasonal and regional contributions to air temperature changes in China

To calculate the regional contributions to air temperature changes in China, the following method was used in this study. The contribution $X(i)$ from each region to the national terrestrial average air temperature rate of increase was calculated using:

$$
X(i)=\frac{A(i) \times S(i)}{\sum_{i=1}^{N}[A(i) \times S(i)]} \times 100 \%
$$

where $A(i)$ is the trend magnitude of average air temperature of the $i$-th region in a certain period and $S(i)$ is the percentage of the land area of the $i$-th region in the total land area of whole country. According to the comprehensive geographical division of China (Zhao et al., 1983), the percentages from the monsoon region in eastern China, arid region of northwestern China, and high frigid region of the Tibetan Plateau in the total land area of China were $45 \%, 30 \%$ and $25 \%$, respectively.

Similarly, the contribution $\Delta X(i)$ from different regions to the warming hiatus in China was calculated using:

$$
\Delta X(i)=\frac{\left[A_{2}(i)-A_{1}(i)\right] \times S(i)}{\sum_{i=1}^{N}\left[A_{2}(i)-A_{1}(i)\right] \times S(i)} \times 100 \%
$$

where $A_{1}(i)$ is the magnitude of the trend in average air temperature in the region of the previous period (i.e. the nationwide warming acceleration period 1960-1998), and $A_{2}(i)$ is the latter period (i.e. the nationwide warming hiatus period 1998-2012).

The seasonal contribution proportions $Y(i)$ to air temperature changes in China were calculated as:

$$
Y(i)=\frac{B(k) \times 1 / T}{\sum_{i=1}^{N}[B(k) \times 1 / T]} \times 100 \%
$$

where $B(k)$ is the magnitude of the trend in average air temperature of the $k$-th seasonal region, $T=4$, representing four seasons.

The seasonal contribution proportions $\Delta Y(i)$ to the warming hiatus in China were calculated as: 


$$
\Delta Y(i)=\frac{\left[B_{2}(k)-B_{1}(k)\right] \times 1 / T}{\sum_{i=1}^{N}\left[B_{2}(k)-B_{1}(k)\right] \times 1 / T} \times 100 \%
$$

where $B_{1}(k)$ is magnitude of the trend in average air temperature of the $k$-th season in each region in the previous period (i.e., nationwide warming acceleration period of 1960-1998) and $B_{2}(k)$ is the latter period (i.e., nationwide warming hiatus period of 1998-2012).

To determine the seasonal and regional contributions to air temperature change in China, this study defined the 1960-1998 as the warming acceleration period, which is convenient for calculation and analysis.

\subsubsection{Wavelet analysis}

Wavelet analysis is widely used in climate, hydrology, and other fields. In this study, the Morlet wavelet is used to analyze the cycles and wavelet variance is used to determine the main cycles.

\section{Results and analysis}

\subsection{Air temperature changes in China due to the warming hiatus}

\subsubsection{Interannual variations}

As shown in Table 1, the global (land and ocean) warming rate was $0.04^{\circ} \mathrm{C} / 10 \mathrm{a}$ for 1998-2012, which was significantly slower than that for $1951-2012$, at $0.117^{\circ} \mathrm{C} / 10 \mathrm{a}$. However, the global average surface temperature rose rapidly after 2000, indicating that the 1998-2012 warming hiatus was short. However, over the 15-year hiatus, the spatial and temporal distribution of surface temperature is inconsistent on a global scale (Trenberth et al., 2014). For instance, global ocean surface mean temperatures over 1998-2012 slightly decreased compared with 1951-2012, while the decline over global land is clear.

Table 1 Magnitude of average air temperature trends globally (IPCC, Climate Change 2013) and in China during different periods

\begin{tabular}{cccccc}
\hline & & \multicolumn{4}{c}{ Air temperature trend $\left({ }^{\circ} \mathrm{C} / 10 \mathrm{a}\right)$} \\
\cline { 3 - 6 } & & $1951-2012$ & $1998-2012$ & $1998-2014$ & $2000-2014$ \\
\hline \multirow{3}{*}{ Globe } & Land and ocean & 0.117 & 0.04 & 0.059 & 0.116 \\
& Land & 0.194 & 0.039 & 0.112 & 0.15 \\
& Ocean & 0.088 & 0.014 & 0.038 & 0.036 \\
\hline \multirow{2}{*}{ China } & Land & - & -0.221 & -0.094 & 0.018 \\
\hline
\end{tabular}

Comparing terrestrial average air temperature anomalies across the globe, in the Northern Hemisphere and China (Figure 2), four datasets show an upward trend in average temperature globally and in the Northern Hemisphere since 1980 (Figures 2a and 2b). Within the long-term trend, 1980-1998 showed accelerating temperature growth. The trend in air temperature was $0.039^{\circ} \mathrm{C} / 10 \mathrm{a}$ globally for $1998-2012$, which was about a fifth of that during 1951-2012, as was the Northern Hemisphere. In China, the overall air temperature from 1960 to 2016 rose significantly at $0.274^{\circ} \mathrm{C} / 10 \mathrm{a}$, reaching a total increase of $1.56^{\circ} \mathrm{C}$ in this period (Figure 2c). Since the 1980s, air temperature increased rapidly and reached its peak in 
1998, and then fluctuated until it fell to a trough in 2012, with a significant cooling trend $\left(-0.221^{\circ} \mathrm{C} / 10 \mathrm{a}\right)$ for $1998-2012$. Karl et al. (2015) found significant cooling trend at the mid-latitude land after the beginning of the 21 st century. This agreement indicates that China exhibited the same warming hiatus as the global and Northern Hemisphere land for 1998-2012. Globally, in the Northern Hemisphere and China, air temperatures rose rapidly after 2012, suggesting that the warming hiatus during this period was transient. Furthermore, average air temperatures over 1998-2012 were higher than the multi-year average, suggesting that temperature did not decrease sharply. Nevertheless, the warming hiatus over 1998-2012 should not be ignored, because greenhouse gas concentrations increased continuously over the 15-year period while air temperature did not show a significant linear warming trend, and many models have been unable simulate the warming hiatus (Wang et al., 2014); therefore, the mechanism needs further study.
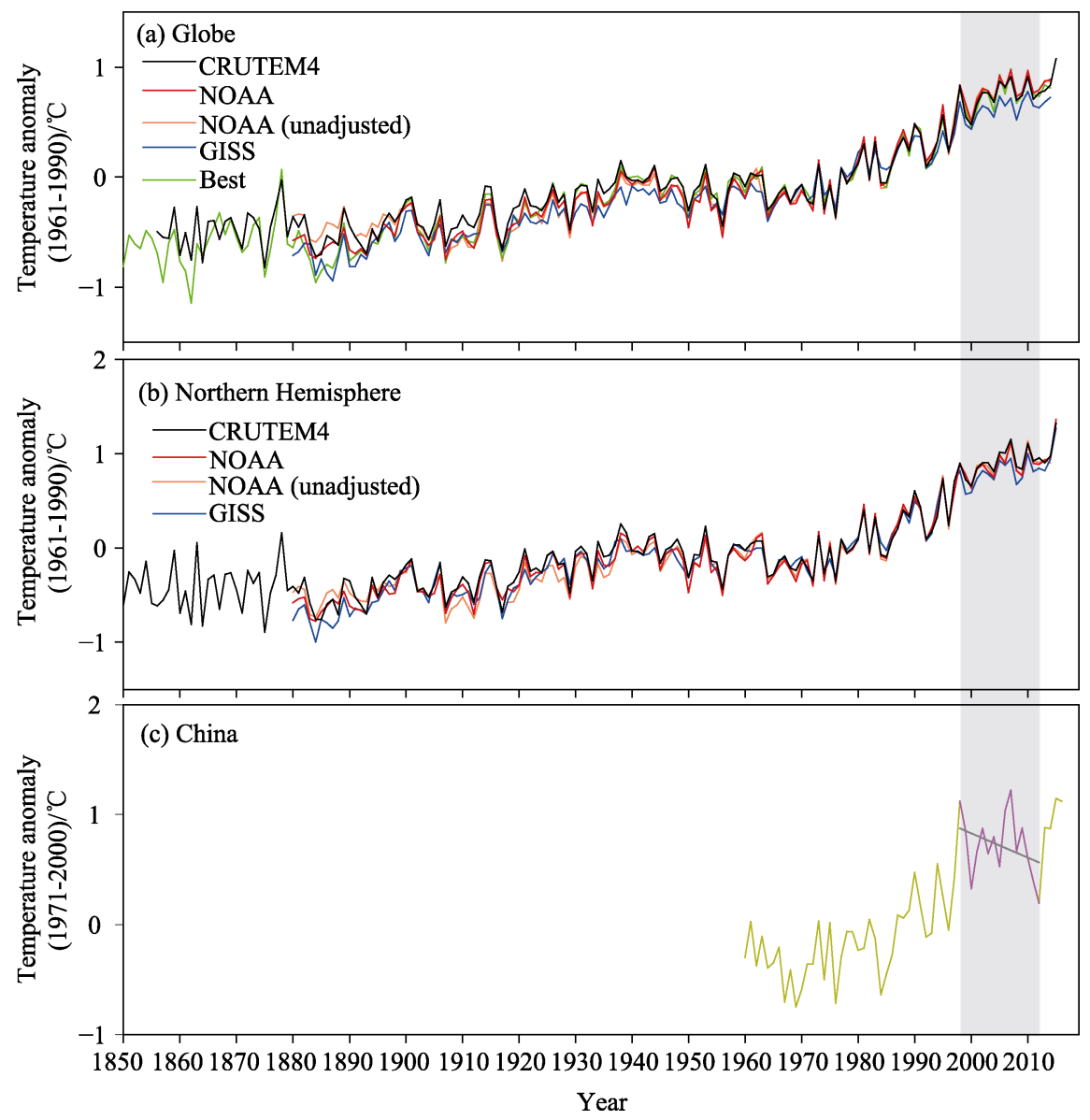

Notes: Global and Northern Hemisphere data based on CRUTEM4 (Jones et al., 2012), NCEI/NOAA (Karl et al., 2015), GISS (Hansen et al., 2010), and Berkeley Earth (http://berkeleyearth.lbl.gov/regions/global-land); unadjusted data are from NCEI (Karl et al., 2015). All data are expressed as anomalies from the 1961-1990 average. The shaded area indicates the global warming hiatus period, 1998-2012.

Figure 2 Terrestrial average air temperature anomalies globally, in the Northern Hemisphere and China

\subsubsection{Seasonal variations}

Some studies have shown that global surface temperatures have decreased in winter and in- 
creased in summer since 1998 (Kosaka et al., 2013). In the Northern Hemisphere, warming hiatus in winter was more pronounced than in summer (Kosaka et al., 2013; Trenberth et al., 2014). In China, temperatures significantly decreased in winter during the warming hiatus (Figure 3). The trend in winter was $-0.826^{\circ} \mathrm{C} / 10 \mathrm{a}$ for $1998-2012$, which is lower than the long-term trend over $1960-2012$ by $1.18^{\circ} \mathrm{C} / 10 \mathrm{a}$; winter accounts for $74.13 \%$ of the national cooling trend whereas spring and autumn had trends of $-0.198^{\circ} \mathrm{C} / 10 \mathrm{a}$ and $-0.041^{\circ} \mathrm{C} / 10 \mathrm{a}$ and corresponding contributions of $19.16 \%$ and $13.29 \%$, respectively (Table 2 ). In summer, the trend was $0.198^{\circ} \mathrm{C} / 10 \mathrm{a}$, which was slightly higher than that during 1960-2012, and higher than the warming acceleration period from 1960 to 1998 by $0.117^{\circ} \mathrm{C} / 10 \mathrm{a}$; the contribution to warming hiatus was $-6.59 \%$ (Table 2 ). Generally, of the seasons, the winter warming rate was fastest before 1998 (Figure 3), but dropped sharply after 1998, and there was a big difference before and after 1998. In addition, in both the accelerated warming and warming hiatus periods, summer continued to warm at a relatively stable rate. After 2000, spring, summer, and autumn showed warming in all seasons except winter.

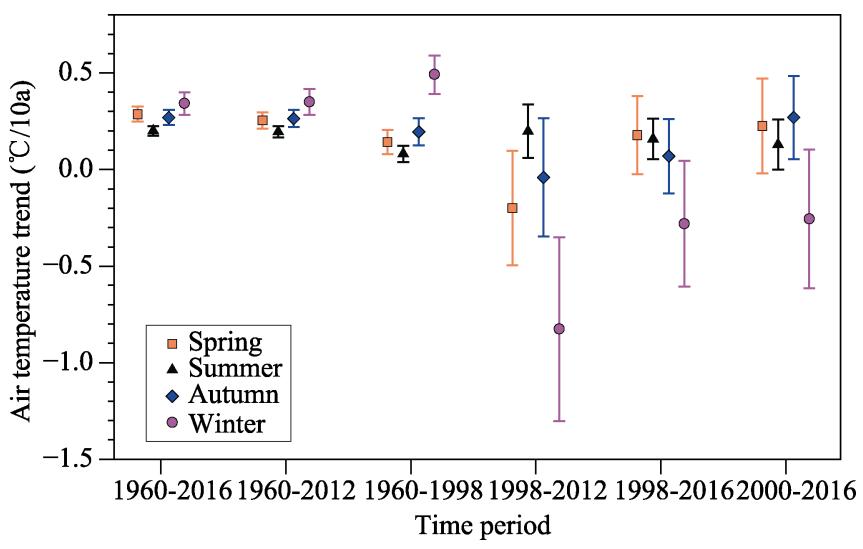

Figure 3 Trends in average air temperature in China for each season during different periods (error bars denote the $90 \%$ confidence interval)

Table 2 Seasonal contributions to air temperature changes in China for different periods

\begin{tabular}{lcccc}
\hline \multirow{2}{*}{ Time periods } & \multicolumn{4}{c}{ Contribution (\%) } \\
\cline { 2 - 5 } $1960-2016$ & Spring & Summer & Autumn & Winter \\
1960-2012 & 26.13 & 18.25 & 24.5 & 31.12 \\
$1960-1998$ (Acceleration period) & 23.93 & 18.37 & 24.8 & 32.9 \\
$1998-2012$ (Hiatus period) & 15.62 & 8.9 & 21.46 & 54.01 \\
$1998-2016$ & 22.87 & -22.82 & 4.73 & 95.22 \\
$2000-2016$ & 143.5 & 24.50 & 55.69 & -226.36 \\
$1998-2012$ and 1960-1998 & 61.39 & 35.11 & 73.41 & 69.81 \\
(Proportional contribution to warming hiatus) & 19.16 & -6.59 & 13.29 & 74.13 \\
\hline
\end{tabular}

\subsubsection{Periodic variations}

Figure 4 shows the wavelet transform coefficient time frequency and wavelet variance dia- 
grams of mean temperature in China; the strength of the signals in the transform coefficient diagram is represented by the depth of different colors. In China, changes in air temperature had oscillation periods of 6,12 , and 29 years (Figure 4a), of which the 12- and 29-year periods occurred throughout the time series. In comparison, the oscillation period of about 6-year began in 1970 and disappeared in 2010. The wavelet variance diagram shows that the 12-year oscillating period was the first main period (Figure $4 \mathrm{~b}$ ), which had a significant effect on national air temperature. Temperature changes over 1998-2012 show four complete cold-warm cycles: low temperature-high temperature-low temperature-high temperature-low temperature. In 2016, the temperature reached that of the warm period cycle, and will likely continue to warm in the future.
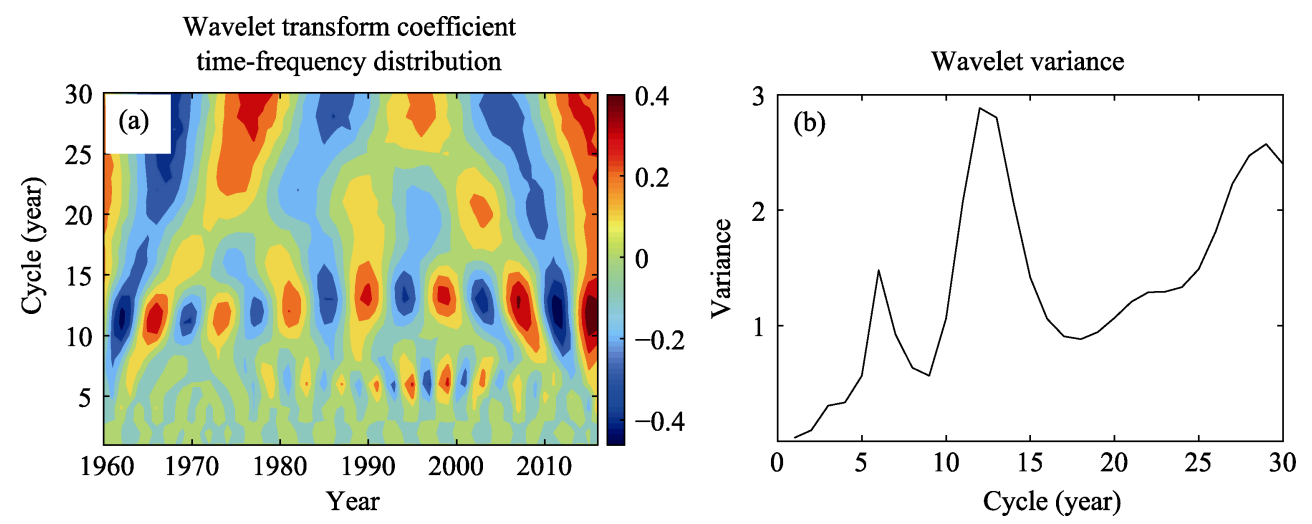

Figure 4 Wavelet analysis of average air temperature in China for 1960-2016

\subsubsection{Spatial variations}

(1) 1960-2012

There was a significant warming trend across all stations in China for 1960-2012 (Figure 5a), of which $95 \%$ of stations showed significant trends. The warming rate in northern China and high frigid region of the Tibetan Plateau was faster than that in southeastern China. In addition, only 5\% of stations showed cooling trends, i.e., 6 stations out of 12 were significant at the 5\% level and 6 were located in Yunnan and Sichuan Provinces. On a seasonal scale (Figures 5b-5e), most areas of China warmed in winter, and only half of the stations were not significant at the 5\% level. Furthermore, only the southern part of the eastern monsoon region warmed slowly and temperature changes in spring and autumn were similar to annual. The warming rates for all the stations across the country were generally small in summer, and 168 showed cooling, mainly concentrated in the Yellow River Basin and the middle-lower reaches of the Yangtze River.

(2) 1998-2012

For 1998-2012, 78.3\% of stations (487) showed cooling trends (Figure 6a), 25.1\% of the stations (156) were significant at the 5\% level, and only $21.7 \%$ (135) showed warming. Among them, the stations with cooling trends are mainly distributed in the northwestern arid region and eastern monsoon region; of these, most parts of Yunnan showed increasing temperatures. Stations with significant cooling trends are mainly concentrated at the junction of the northwestern arid region and eastern monsoon region. In the high frigid region of the 
Tibetan Plateau, $80 \%$ of the stations showed warming and only $20 \%$ showed cooling. From a seasonal perspective (Figures 6b-6e), most parts of China showed cooling in winter and only the high frigid region of the Tibetan Plateau and parts of Yunnan showed warming. In summer, $70.3 \%$ of the stations showed significant warming, and only $29.7 \%$ showed cooling.
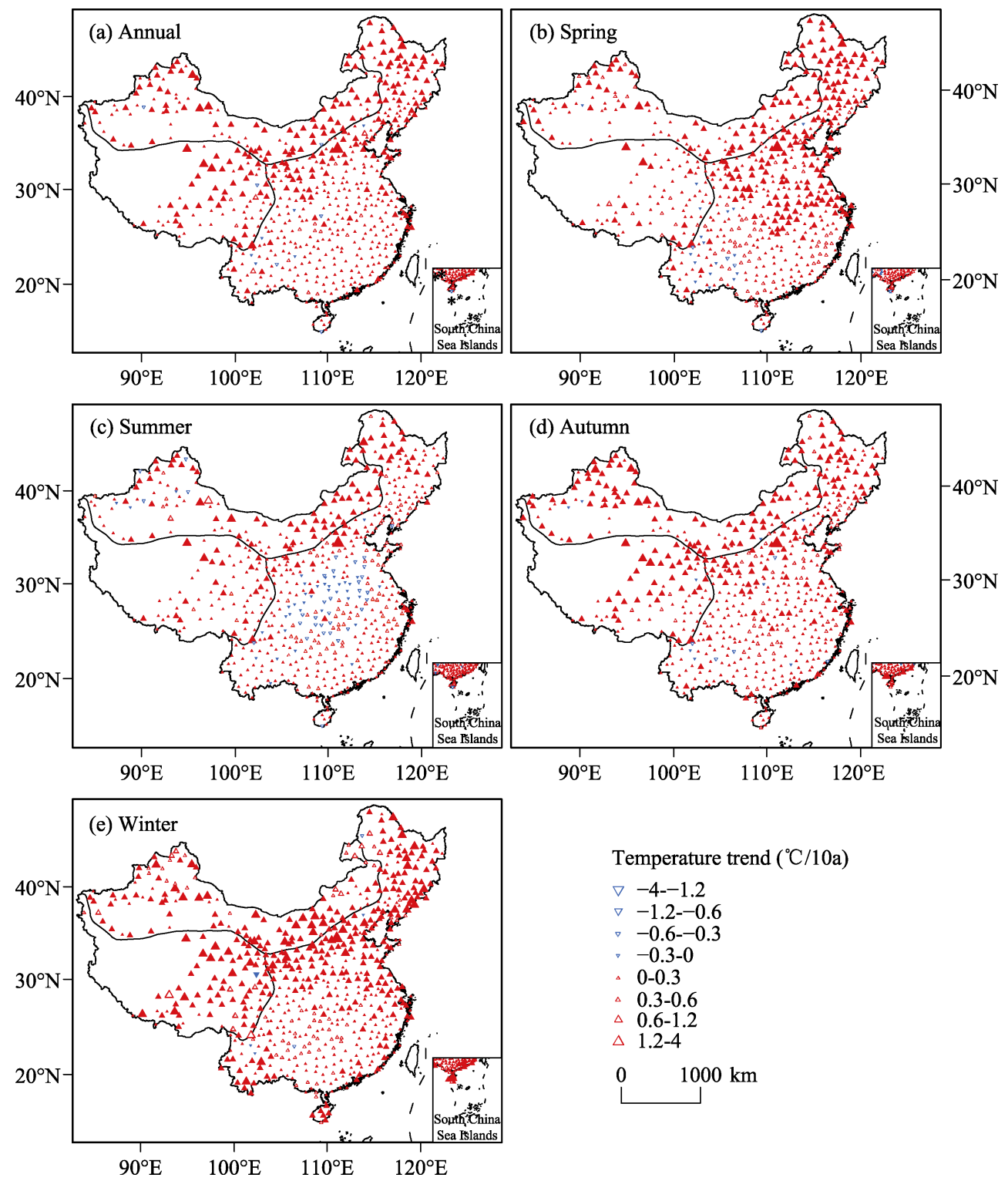

Figure 5 Spatial distribution of trends in annual/seasonal average air temperatures in China for 1960-2012

(3) 2000-2016

After 2000, 71.5\% of the stations in China showed warming trends (Figure 7a), of which $17.5 \%$ (109) with significant warming trend concentrated in the Tibetan Plateau and Yunnan. Cooling occurred in $28.5 \%$ of the stations (177), mainly in the eastern monsoon region, western and northeastern parts of the arid northwestern region. In terms of season 

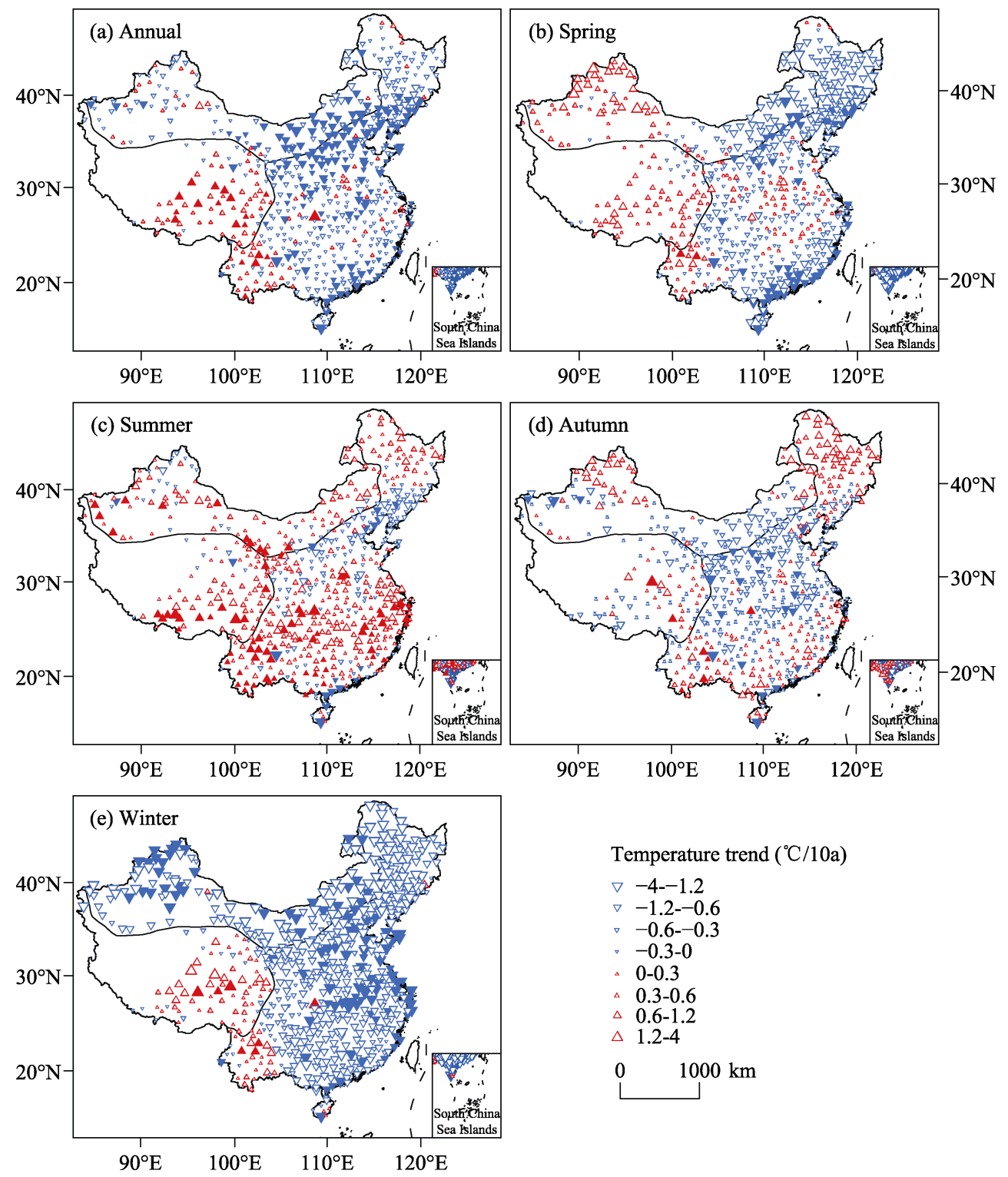

Temperature trend $\left({ }^{\circ} \mathrm{C} / 10 \mathrm{a}\right)$

$\nabla-4--1.2$

$\nabla-1.2--0.6$

$\checkmark-0.6-0.3$

$-0.3-0$

$\therefore 0-0.3$

$\triangle 0.3-0.6$

$\Delta 0.6-1.2$

$\triangle 1.2-4$

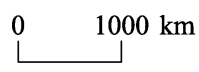

Figure 6 Spatial distribution of trends in annual/seasonal average air temperatures in China for 1998-2012

(Figures $7 \mathrm{~b}-7 \mathrm{e}$ ), variations in air temperature were significant. In winter, $77.8 \%$ of stations (484) showed cooling and 22.2\% (138) showed warming; in autumn, 58.4\% (363) showed warming, of which $18.2 \%$ (113) was significant, and $21.1 \%$ (131) showing cooling mainly distributed in the northern part of the eastern monsoon region and the western part of the northwestern arid region. In spring and summer, air temperatures across the Tibetan Plateau and parts of Yunnan Province increased significantly.

\subsection{Air temperature changes in three geographic zones in response to the warming hiatus}

\subsubsection{Interannual variations}

Comparing the trends found nationally and for the three geographic zones in China (Figure 8), 
we find significant differences in the responses of the three geographic zones to the global warming hiatus. Generally, the three geographic zones showed significant warming trends for 1960-2016, 1960-1998, and 1960-2012. The eastern monsoon and northwestern arid regions showed significant cooling trends over 1998-2012, and the cooling rates exceeded the national average. The northwestern arid region contributed the most, $46.98 \%$ and -0.361 ${ }^{\circ} \mathrm{C} / 10 \mathrm{a}$, followed by the eastern monsoon region, $53.79 \%$ and $-0.31{ }^{\circ} \mathrm{C} / 10 \mathrm{a}$ (Table 3 ); clearly, both areas responded significantly to the hiatus. However, in the Tibetan Plateau, the warming rate was $0.204^{\circ} \mathrm{C} / 10 \mathrm{a}$ for $1998-2012$, which was slightly higher than 1960-1998, slightly lower than 1960-2012; the temperature fluctuations were not significant in other time periods, but the warming was much higher than the warming rate in the eastern mon-
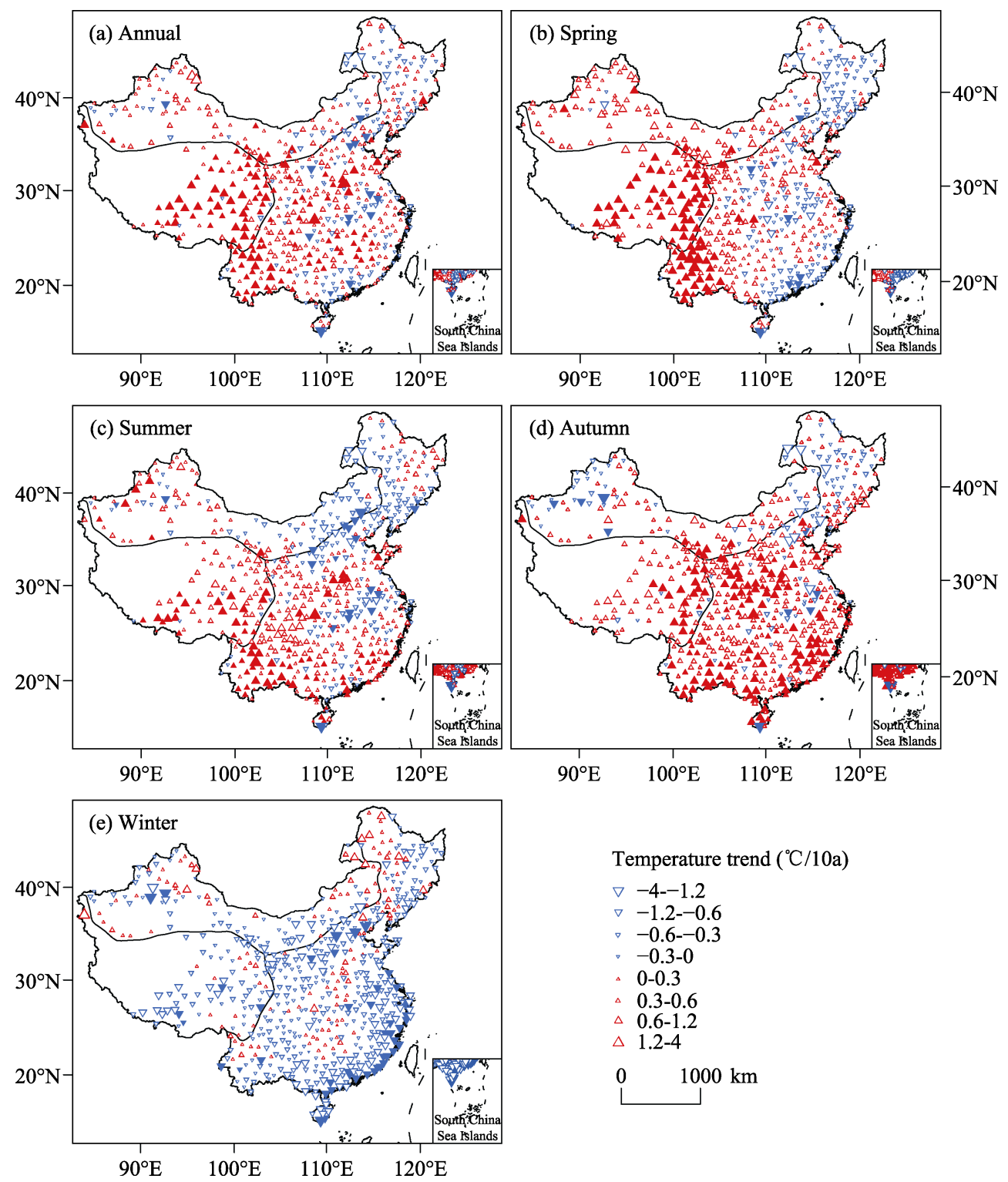

Figure 7 Spatial distribution of trends in annual/seasonal average air temperatures in China over 2000-2016 
Table 3 Regional contribution to air temperature changes in China during different periods

\begin{tabular}{lccc}
\hline \multirow{2}{*}{ Time periods } & \multicolumn{3}{c}{ Contribution (\%) } \\
\cline { 2 - 4 } & $\begin{array}{c}\text { Monsoon region of } \\
\text { eastern China }\end{array}$ & $\begin{array}{c}\text { Arid region of north- } \\
\text { western China }\end{array}$ & $\begin{array}{c}\text { High frigid region of } \\
\text { the Tibetan Plateau }\end{array}$ \\
\hline 1960-2016 & 37.15 & 35.61 & 27.24 \\
$1960-2012$ & 36.86 & 35.75 & 27.39 \\
$1960-1998$ (Acceleration period) & 37.91 & 39.58 & 22.51 \\
1998-2012 (Hiatus period) & 70.89 & 54.96 & 25.85 \\
$1998-2016$ & -7.29 & 9.84 & 97.46 \\
2000-2016 & 25.68 & 25.94 & 59.25 \\
1998-2012 and 1960-1998 & 53.79 & 46.98 & -0.77 \\
(Proportional contribution to warming hiatus) & & & \\
\hline
\end{tabular}

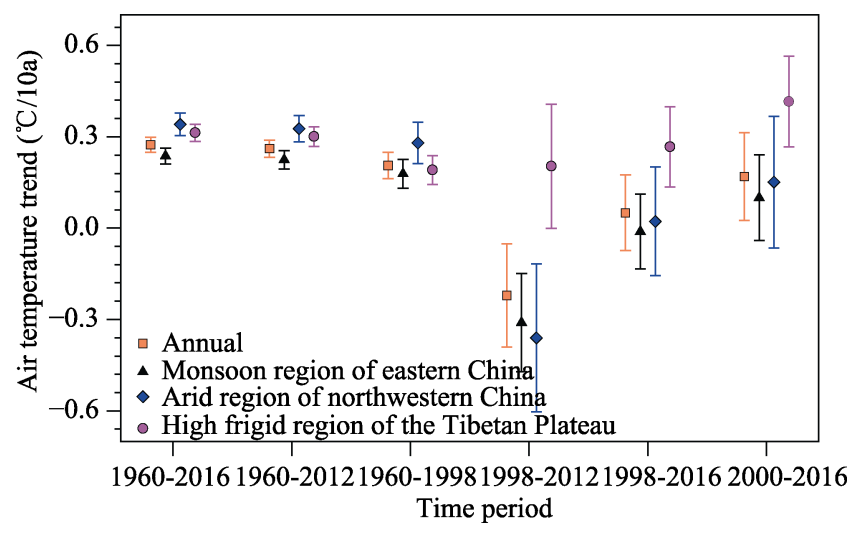

Figure 8 Trends in average air temperature for China and the three geographic zones during different periods (error bars denote the $90 \%$ confidence interval)

soon and northwest arid regions during the same period. The Tibetan Plateau contributed $-70 \%$ without the warming hiatus (Table 3). Duan et al. (2016) pointed out that the temperature and precipitation on the Tibetan Plateau accelerated under the background of global warming. The results from this study show that the high frigid region of the Tibetan Plateau warmed at a higher rate in different periods. Before 1998, the contribution to warming temperatures was smaller than that from the eastern monsoon and northwest arid regions, but far exceeded the national average after 1998. Particularly after 2000, the warming rate reached a new peak.

3.2.2 Changes in seasonal average air temperature of three geographic zones

Beyond the seasonal differences during the warming hiatus across China, there are differences across the three geographic zones. Table 4 shows the trends in air temperature for three geographic zones across different seasons and periods. Slowed warming in the eastern monsoon region is mainly reflected in changes in winter air temperature, whose trends were $-0.896^{\circ} \mathrm{C} / 10 \mathrm{a}$ in winter and $0.134^{\circ} \mathrm{C} / 10 \mathrm{a}$ in summer for $1998-2012$. In the northwestern arid region, the trend magnitudes were $-1.425^{\circ} \mathrm{C} / 10 \mathrm{a}$ in winter and $0.217^{\circ} \mathrm{C} / 10 \mathrm{a}$ in summer for 1998-2012. The air temperatures in spring and autumn showed insignificant cooling trends. In high frigid region of the Tibetan Plateau, the warming rate was $0.337^{\circ} \mathrm{C} / 10 \mathrm{a}$ in summer 
during 1998-2012, lower in spring and winter, and autumn showed a slight cooling trend. In summary, winter contributed the most to the warming hiatus and summer had the smallest contribution in eastern and northwestern China. In addition, temperature increases were the fastest in summer on the Tibetan Plateau.

Table 4 Trends in seasonal average air temperature for three geographic zones in China

\begin{tabular}{|c|c|c|c|c|c|c|c|c|c|c|c|c|}
\hline \multirow{3}{*}{$\begin{array}{l}\text { Time } \\
\text { period }\end{array}$} & \multicolumn{12}{|c|}{ Temperature trend $\left({ }^{\circ} \mathrm{C} / 10 \mathrm{a}\right)$} \\
\hline & \multicolumn{4}{|c|}{$\begin{array}{l}\text { Monsoon region of } \\
\text { eastern China }\end{array}$} & \multicolumn{4}{|c|}{$\begin{array}{l}\text { Arid region of northwestern } \\
\text { China }\end{array}$} & \multicolumn{4}{|c|}{$\begin{array}{l}\text { High frigid region of the } \\
\text { Tibetan Plateau }\end{array}$} \\
\hline & Spring & Summer & Autumn & Winter & Spring & Summer & Autumn & Winter & Spring & Summer & Autumn & Winter \\
\hline 1960-2016 & 0.271 & 0.153 & 0.227 & 0.316 & 0.36 & 0.276 & 0.334 & 0.39 & 0.245 & 0.272 & 0.319 & 0.313 \\
\hline 1960-2012 & 0.24 & 0.146 & 0.217 & 0.314 & 0.308 & 0.286 & 0.345 & 0.388 & 0.227 & 0.257 & 0.302 & 0.301 \\
\hline 1960-1998 & 0.145 & 0.058 & 0.15 & 0.461 & 0.146 & 0.085 & 0.269 & 0.702 & 0.128 & 0.148 & 0.236 & 0.191 \\
\hline 1998-2012 & -0.419 & 0.134 & -0.063 & -0.896 & -0.061 & 0.217 & -0.059 & -1.425 & 0.213 & 0.337 & -0.046 & 0.204 \\
\hline 1998-2016 & 0.04 & 0.128 & 0.066 & -0.248 & 0.397 & 0.054 & -0.051 & -0.421 & 0.281 & 0.324 & 0.205 & 0.267 \\
\hline 2000-2016 & 0.069 & 0.087 & 0.277 & -0.212 & 0.325 & -0.008 & 0.129 & -0.245 & 0.596 & 0.375 & 0.429 & -0.27 \\
\hline
\end{tabular}

\subsubsection{Periodic variations}

Figure 9 shows the periodic variations in average air temperature of the three geographic zones for 1960-2016. The eastern monsoon region was similar to the national variations (Figures 9a1 and 9a2), and average temperature mainly had an oscillation period of about 6, 13, and 29 years; of these, the 13-year period appeared as the first clear period for 1960-2016. The 6-year period began to show clearly in 1980 and gradually disappeared in 2010. In the northwest arid region (Figures $9 \mathrm{~b} 1$ and 9b2), there were 6-, 12-, and 30-year oscillations, among which the period of around 12 years was the main period, which was clear throughout 1960-2016. In addition, the 6-year period did not appear until 1980, and gradually disappeared after 2000. In the Tibetan Plateau, there were periodic variations of 8 , 11,23 , and 29 years, among which the 29-year period was dominant; the 11- and 8-year periods alternated: the 11-year period disappeared in 1985 when the 8-year period appeared and the 11-year period appeared again in 2000 (Figures 9c1 and 9c2).

During the warming hiatus, there were four periodic variations in the eastern monsoon region of $6,13,20$, and 29 years. The cyclical changes around 13 years and 29 years were relatively stable. The temperature change in this region presented a negative-positive-negative-positive oscillation, and the 6-year period disappeared in 2004. In the arid region of northwestern China, the main periodic variation was about 12 years, and average temperature showed a negative-positive-negative-positive oscillation. In the Tibetan Plateau, there were oscillation periods of 13,21 , and 29 years, and the 29 years was stable.

\subsection{Possible factors affecting the 1998-2012 warming hiatus in China}

\subsubsection{The influence of Pacific Decadal Oscillation (PDO)}

The Pacific Decadal Oscillation (PDO) is considered an important modality affecting climate change in the Northern Hemisphere, especially because the climate of the Pacific Ocean and its surrounding areas, including coastal areas in China, change on an interdecadal scale (Schneider et al., 2005). Figure 10 shows the time series of PDO index and average 

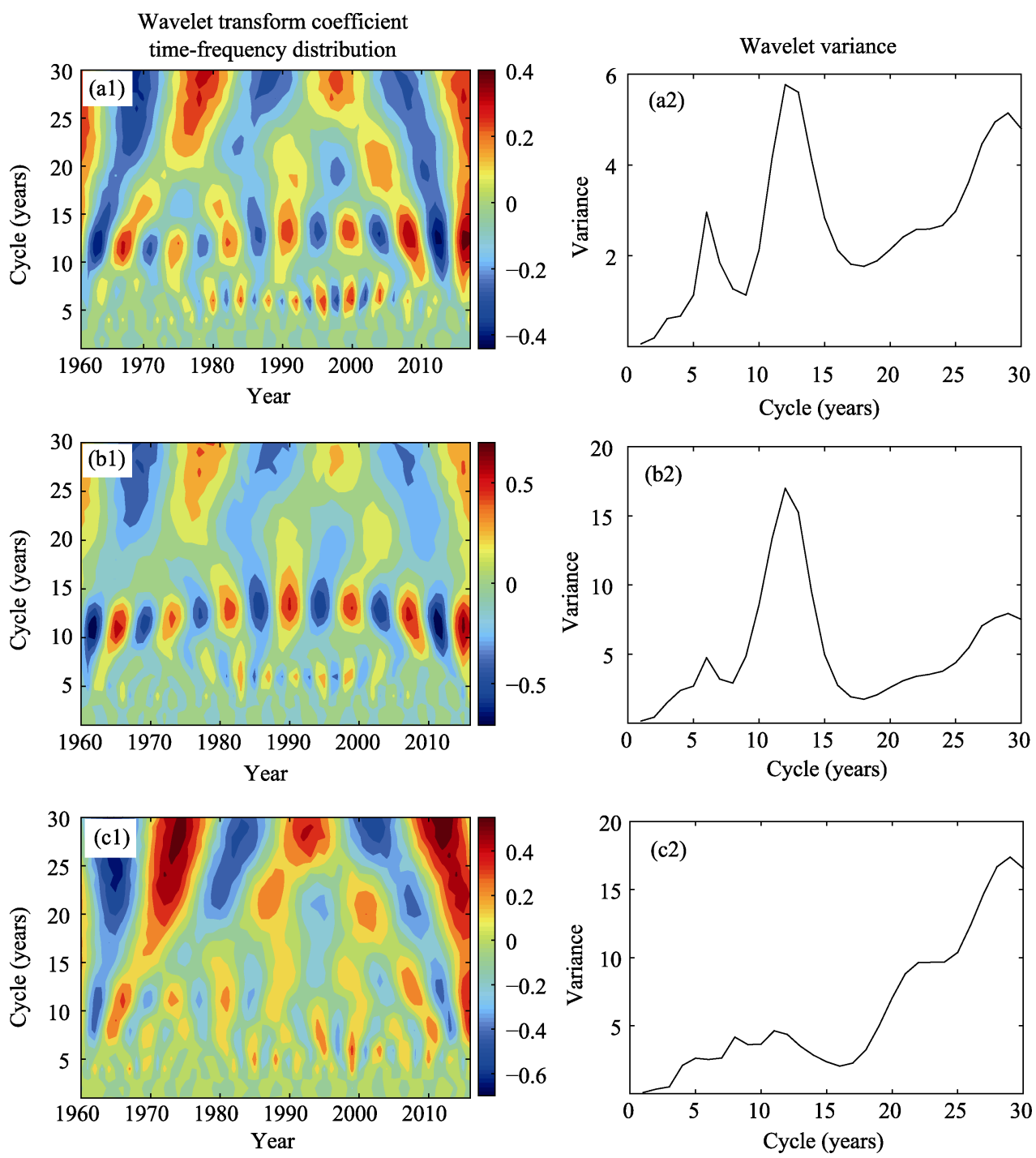

Figure 9 Wavelet analysis of average air temperature in the monsoon region of eastern China (a1 and a2), arid region of northwestern China (b1 and b2), and high frigid region of the Tibetan Plateau (c1 and c2) for 1960-2016

air temperature anomaly of China using an annual scale (Figures 10a1 and 10b1). For this discussion, a positive PDO index is termed the PDO positive phase and negative PDO index is termed the PDO negative phase. The PDO index transitioned from negative to positive in the late 1970s and from positive to negative in the mid-1990s, a negative-positive-negativepositive change. From the 1960s to the end of the 1970s, when China's average air temperature showed a downward trend, the PDO was in a negative phase; in the 1980s, the temperature rose rapidly and the PDO was in a positive phase; in 1998, the temperature growth rate slowed down significantly, and PDO was in a negative phase; in 2012, the temperature rose significantly at the beginning of the year and the PDO was in a positive phase. Therefore, the increase or decrease of air temperature in China is correlated and may be regulated by the positive or negative PDO phases. During the 1998-2012 warming hiatus, the PDO was in a negative phase, and the PDO index was positively correlated with temperature in 
China and the warming hiatus in China may have been regulated by the negative PDO phase. However, after 2012, the PDO phase transitioned from negative to positive. The relationship between temperature and PDO index on the seasonal scale is shown in Figures 10b and 10c. In summer, the PDO index was negatively correlated with average air temperature anomalies, and the temperature increases in the positive phase of PDO were small, while temperature increases in the negative phase of PDO were large. In winter, the PDO index showed an upward fluctuating trend but there were no clear changes in the positive and negative phases.

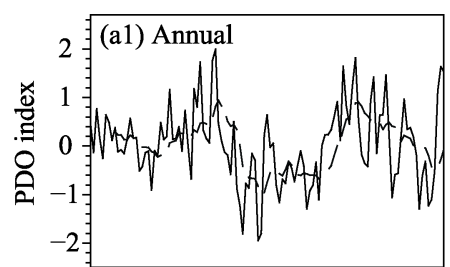

190019201940196019802000

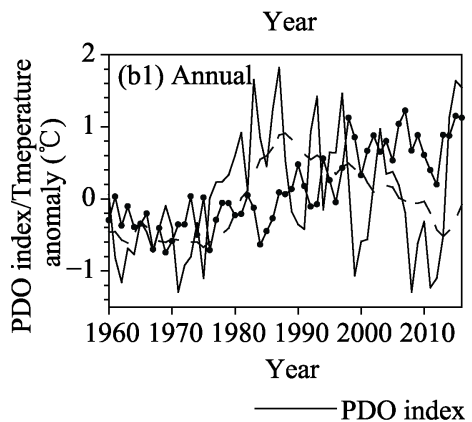

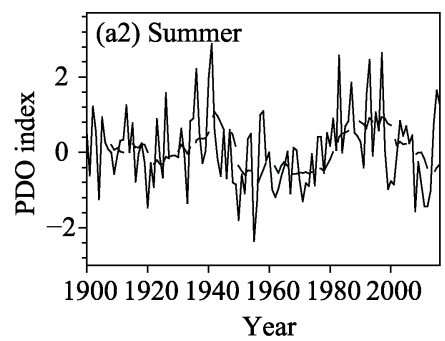

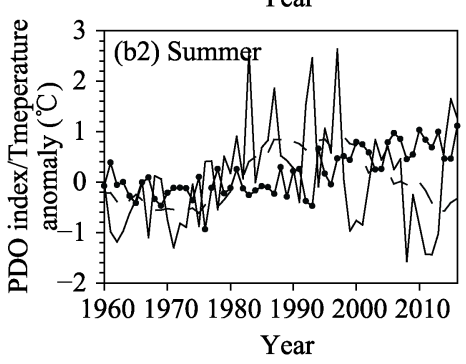

- PDO index 9-year moving average
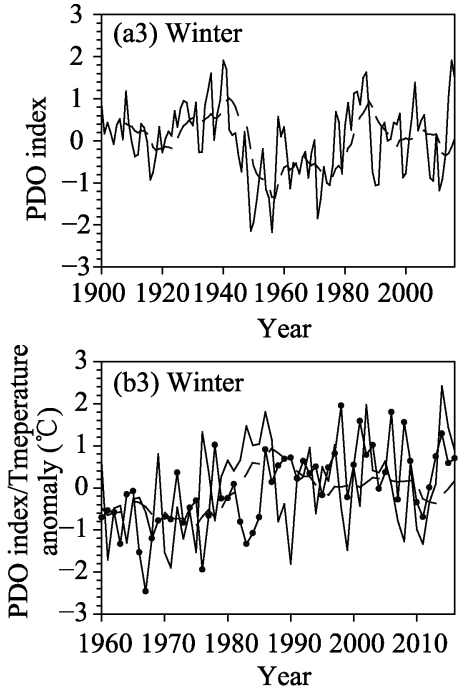

Figure 10 Changes in PDO index and average air temperature anomalies in China for 1900-2016 (a1, a2 and a3) and 1960-2016 (b1, b2 and b3)

According to the positive and negative phase of the PDO, air temperature in China is divided into three periods: 1960-1976 (PDO negative phase), 1977-1998 (PDO positive phase) and 1999-2013 (PDO negative phase). For 1960-1976, the PDO index was positively correlated with average air temperature in the Tibetan Plateau and southern Yunnan Province and there was a significant negative correlation between PDO index and average air temperature in northeastern China (Figure 11a). For 1977-1988, there was a significant positive

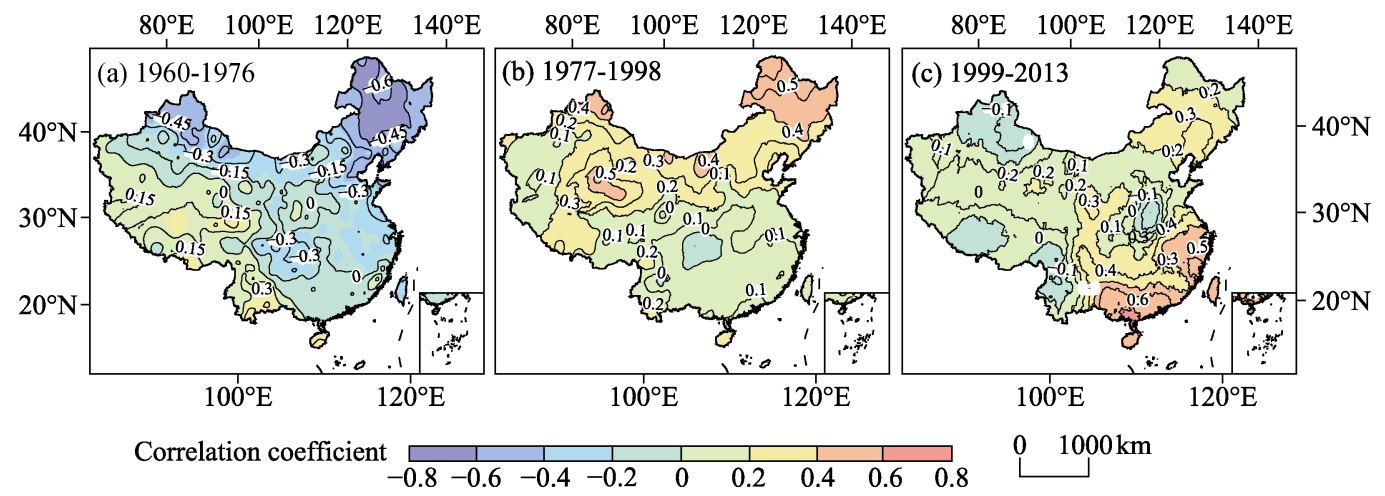

Figure 11 Spatial distribution of correlation coefficient between PDO index and average air temperature in China for different time periods 
correlation between PDO index and average air temperature in the Inner Mongolia Autonomous Region, Gansu Province, northern Xinjiang Uygur Autonomous Region, and northeastern China (Figure 11b). For 1999-2013, the positive correlation between PDO index and average air temperature in the southeastern coastal region (Figure 11c) was significant.

In summary, different phases of the PDO showed regionally different impacts. In addition, the mechanism by which the PDO influenced air temperature varied. During the positive phase of the PDO, the tropical Middle East Pacific was unusually warm, the Aleutian low pressure and westerly winds were strengthened, the North Pacific was cold in the central and western regions, and the warmth of the equatorial central and eastern Pacific, the North American coast, and the Alaska Gulf cause changes in atmospheric circulation. The negative phase of the PDO is just the opposite (Liu, 2016), which should influence air temperature in China.

\subsubsection{Sunspot numbers (SSN) and total solar irradiance (TSI)}

The relationship between global climate change and solar activity has been a popular topic in climate research (Hoyt et al., 1997; Lean, 2010; Coddington et al., 2016). Sunspots are one of the most commonly used parameters for describing solar activity. The sunspot number (SSN) is also the solar activity parameter with the longest observational data record (Friis-Christensen et al., 1991). Previous scholars had revealed the impact of solar activity on climate change by analyzing the relationship between sunspot numbers and temperature (Rathod et al., 2017; Cohen et al., 2009). This study found a similar trend in sunspot number fluctuations for 1700-2016 (Figure 12a1).

From 1960 to 2016, there were five peak years for sunspot numbers: 1968, 1979, 1989, 2000, and 2014, and five nadir years: 1964, 1976, 1986, 1996, and 2008. The average air temperature anomalies appear in five extreme years: 1998, 2006, 2007, 2015 and 2016, and five minimum years: 1967, 1969, 1970, 1976 and 1984. We find the maximum and minimum average air temperature anomalies occur mostly in the sunspot activity peaks and nadirs and within 1-2 years. The sunspot number showed a peak, nadir, and high-low transition during 1998-2012, but the overall trend decreased, which is consistent with the temperature trends in China (Figure 12a2). However, the sunspot numbers were negatively correlated with the average air temperature anomalies of China (Figure 12a3), indicating that the change in sunspot numbers did not play a dominant role during the warming hiatus in China. From the interannual variation in total solar irradiation (Figure 12b1), the total solar irradiation increased rapidly in the early 20 th century and has been generally flat since the 1950s. Generally, total solar irradiation increased over 1960-2016, consistent with the overall temperature trend in China. Total solar irradiation showed a decreasing trend for 1998-2012, which may be one explanation for the warming hiatus in China.

As shown in Figure 4, there was a 12-year oscillation cycle in average air temperature in China for 1960-2016. Figure 13 shows that a wavelet analysis of sunspot numbers shows a clear 11-year cycle, indicating that their periodic changes were very similar. Nonetheless, changes in average air temperature in China and sunspot numbers were not synchronous: sunspot numbers entered a nadir in 1960, temperature entered a nadir in 1961, sunspot numbers reached their peak in 1970, and temperature was about to enter a positive period. 
Finally, as sunspot numbers were about to enter a peak period in 2010, temperature was in a negative anomaly period. Clearly, temperature changes in China lagged sunspot numbers, which suggests that temperature might be regulated by sunspot changes. Sunspots were at a low during 1998-2012 while China had a significant cooling trend. Sunspot numbers peaked after 2000 when air temperature in China increased rapidly, so there was better correspondence at that time.
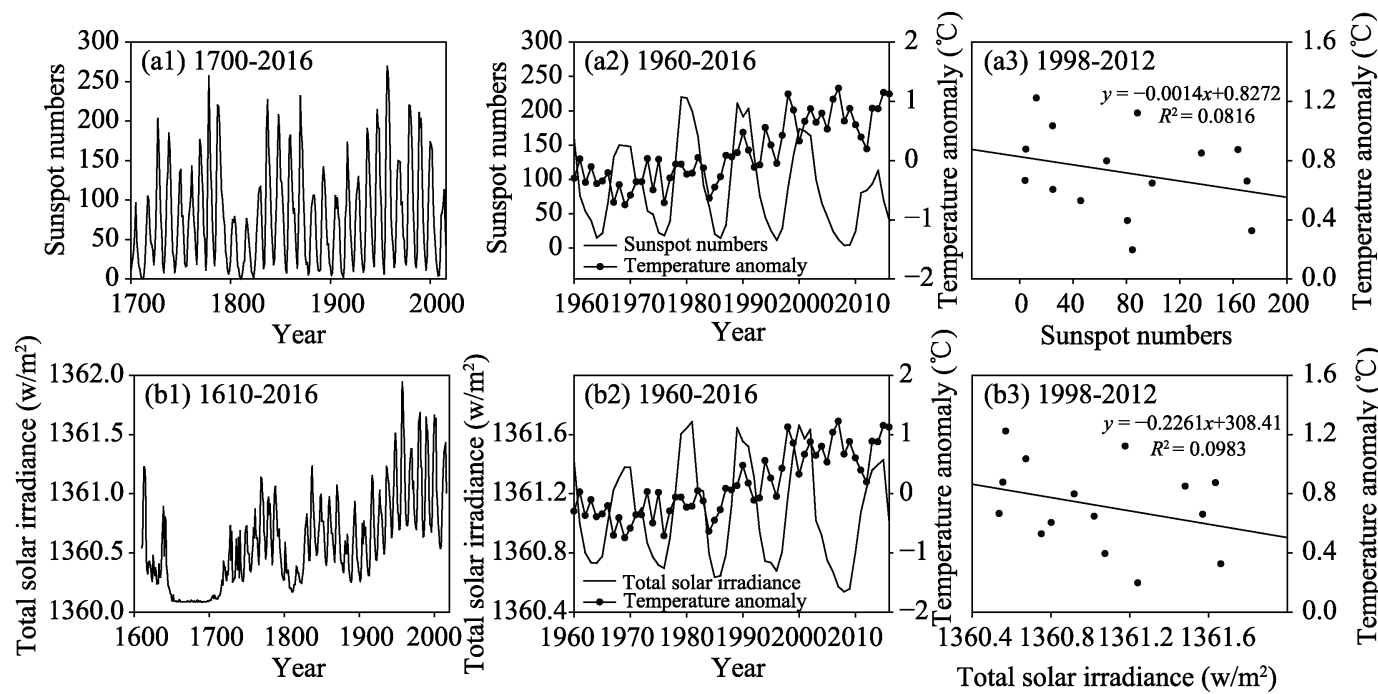

Figure 12 Changes in sunspot numbers, total solar irradiance and average air temperature anomalies in China (a1, a2, b1 and b2) during different periods. Correlation between sunspot numbers, total solar irradiance and average air temperature anomalies in China for 1998-2012 (a3 and b3)
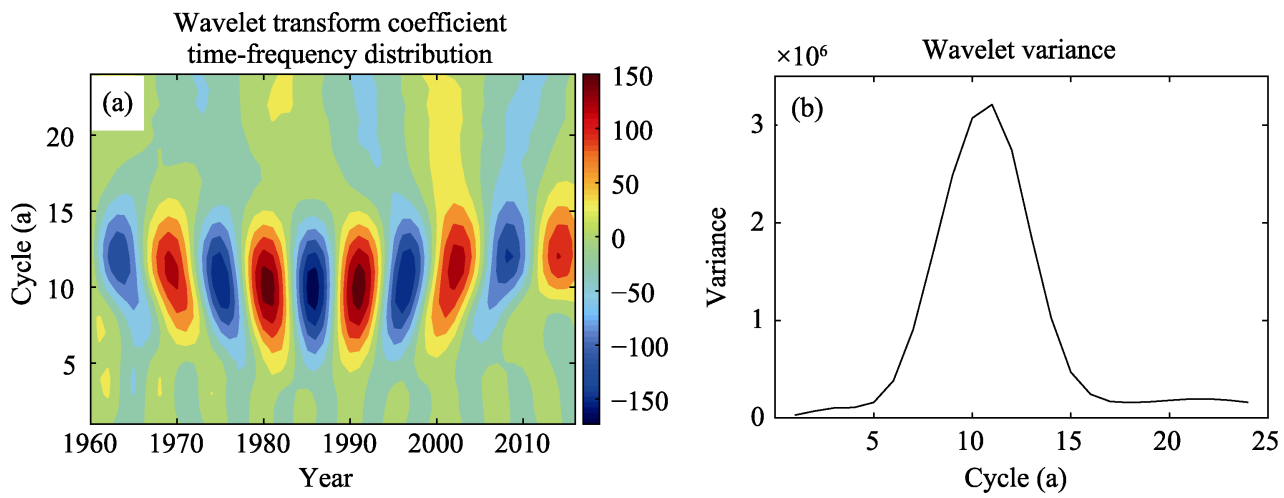

Figure 13 Wavelet analysis of sunspot numbers for 1960-2016

\section{Discussion}

The global warming hiatus has significant spatial heterogeneity and seasonal differences. First, the Arctic region and high frigid region of the Tibetan Plateau in China showed variations from the global average. Huang et al. (2017) found that the Arctic had a significant warming trend for 1998-2012. Similarly, in this study, we found no significant warming hiatus in the Tibetan Plateau, suggesting commonalities between the Arctic region and Ti- 
betan Plateau, but the intrinsic relationship and difference between the two are not clear. An explanation for the two zones showing significant warming trends in the context of global land cooling during 1998-2012 should be explored. Second, from the seasonal scale, winter temperature changes are worthy of attention. In the Northern Hemisphere, there was a systematic weakening of the surface temperature trend from warming to nearly neutral or even cooling in winter over the extratropical continents in the last decade (Cohen $\mathrm{J}$ et al., 2009). In Eurasia and most of the United States, there were persistent winter low temperature and blizzard events during 2009-2010, and winter average temperatures were significantly lower than the average climate (Cattiaux et al., 2010; Seager et al., 2010). In China, winter average temperatures in most areas were lower than the historical mean for 2004-2005 (Ding et al., 2007), and winter average temperatures showed a significant negative anomaly compared with the annual average temperature for 2007-2008 (Zhang et al., 2008; Hong et al., 2009; Wen et al., 2009). This study found significant cooling in winter in China for 1998-2012. Since 2000, China's overall temperature has been increasing, but the temperature decreases in winter remain significant. In future research, additional attention should be given to studying the internal mechanism for the sharp decline in winter temperature in different regions in the past decade.

Many scientists have explored possible formation mechanism for the global warming hiatus (Meehl et al., 2011; Kosaka et al., 2013; Li et al., 2013; Schmidt et al., 2014; Dai et al., 2015; Yao et al., 2016). For example, researchers have proposed that the hiatus is related to the state of La Nina (Meehl et al., 2011; Kosaka et al., 2013); the superposition of radiation changes caused by volcanic activity and solar activity and the evolution of El Niño in natural variability (Schmidt et al., 2014); and interdecadal variations in the Pacific (IPO) (Dai et al., 2015), North Atlantic Oscillation (NAO) (Li et al., 2013) and PDO (Douville et al., 2015; Yao et al., 2016). The proposed mechanisms can be divided into two categories, one is external forcing, e.g., solar radiation and volcanic eruption aerosols, the other one is natural internal variability, the most important of which is the impact of the ocean. However, previous studies had not quantified the relative contribution of the two to warming hiatus, nor had they clarified the complex interactions between various formation mechanisms. Because there have been few studies on the internal mechanism of China's cooling during 1998-2012, this study is a step forward. We found that PDO was in a negative phase period during 1998-2012, and the number of sunspots and total solar radiation were reduced, which may cause the slowing of temperature increase in China, but the path and mechanism of PDO impact on climate change in China remains unclear. What is the relationship between PDO activity and solar activity? What is the relationship with other influencing factors? Further research is needed in the future.

In addition, the analysis only accurately reflects air temperature trends in China based on the measured data, which has only been collected for 57 years. The short time series is still insufficient for studying long-term climate change. The use of reliable reconfigurable data to study long-term temperature trends is a goal of the next step.

\section{Conclusions}

(1) For $1998-2012$, the overall air temperature trend in China was $-0.221^{\circ} \mathrm{C} / 10 \mathrm{a}$, which 
was lower than the long-term trends for $1960-1998,1960-2012$, and $1960-2016$ by $0.427^{\circ} \mathrm{C}$ $/ 10 \mathrm{a}, 0.483^{\circ} \mathrm{C} / 10 \mathrm{a}$, and $0.495^{\circ} \mathrm{C} / 10 \mathrm{a}$, respectively. There was a warming hiatus in China that was more significant than the global mean based a comparison of temperature changes in China with global and Northern Hemisphere changes. Seasonally, changes in winter played a dominant role in the nationwide warming hiatus (contributing 74.13\%), and summer had a significant warming trend. Comparing the three geographic zones, eastern and northwestern China showed cooling trends, $-0.361^{\circ} \mathrm{C} / 10 \mathrm{a}$ and $-0.31^{\circ} \mathrm{C} / 10 \mathrm{a}$, respectively, far exceeding the nationwide mean. Eastern China played a dominant role in the nationwide warming hiatus, contributing 53.79\%. On the Tibetan Plateau, air temperature increased $0.204^{\circ} \mathrm{C} / 10 \mathrm{a}$, i.e., without a significant warming hiatus.

(2) For 1998-2012, there were 6-, 12-, and 29-year oscillation cycles in China's temperature variations, of which those at 12-year and 29-year cycles were most clear. A 13-year periodic variation in temperature in the eastern monsoon region was relatively stable. In northwestern China, the temperature changes occurred on a 12-year cycle. On the Tibetan Plateau, the 29-year cycle was significant.

(3) The warming hiatus in China for 1998-2012 may have been influenced by the negative PDO phase and the reduction in sunspot numbers and total solar radiation. We also found that the effects of the PDO varied seasonally.

(4) The warming rate in China slowed down significantly over 1998-2012 compared with the rapid warming over 1960-1998. However, after 2012, air temperature has rapidly increased with a trend of $0.17^{\circ} \mathrm{C} / 10 \mathrm{a}$ and is likely to continue warming in the next few years.

\section{References}

Carter B, 2006. There is a problem with global warming...it stopped in 1998. Telegraph Newspaper, 9.

Cattiaux J, Vautard R, Cassou C et al., 2010. Winter 2010 in Europe: A cold extreme in a warming climate. Geophysical Research Letters, 37: L20704. doi: 10.1029/2010GL044613.

Coddington O, Lean J L, Pilewskie P et al., 2016. A solar irradiance climate data record. Bulletin of the American Meteorological Society, 97(7): 1265-1282.

Cohen J, Barlow M, Saito K, 2009. Decadal fluctuations in planetary wave forcing modulate global warming in late boreal winter. Journal of Climate, 22(16): 4418-4426.

Cowtan K, Way R G, 2014. Coverage bias in the HadCRUT4 temperature series and its impact on recent temperature trends. Quarterly Journal of the Royal Meteorological Society, 140(683): 1935-1944.

Dai A, Fyfe J C, Xie S P et al., 2015. Decadal modulation of global surface temperature by internal climate variability. Nature Climate Change, 5(6): 555-559.

Deser C, Guo R, Lehner F, 2017. The relative contributions of tropical Pacific sea surface temperatures and atmospheric internal variability to the recent global warming hiatus. Geophysical Research Letters, 44(15): 7945-7954.

Ding Y H, Ma X Q, 2007. Analysis of isentropic potential vorticity for a strong cold wave in 2004/2005 winter. Acta Meteorologica Sinica, 65(5): 695-707. (in Chinese)

Douville H, Voldoire A, Geoffroy O, 2015. The recent global warming hiatus: What is the role of Pacific variability? Geophysical Research Letters, 42(3): 880-888.

Duan A M, Xiao Z X, Wu G X, 2016. Characteristics of climate change over the Tibetan Plateau under the global warming during 1979-2014. Climate Change Research, 12(5): 374-381. (in Chinese)

Friis-Christensen E, Lassen K, 1991. Length of the solar cycle: An indicator of solar activity closely associated with climate. Science, 254(5032): 698-700. 
Hansen J, Ruedy R, Sato M et al., 2010. Global surface temperature change. Reviews of Geophysics, 48: RG4004. doi: 10.1029/2010RG000345.

Hassani H, Huang X, Gupta R et al., 2016. Does sunspot numbers cause global temperatures? A reconsideration using non-parametric causality tests. Physica A: Statistical Mechanics and its Applications, 460: 54-65.

Hong C, Li T, 2009. The extreme cold anomaly over Southeast Asia in February 2008: Roles of ISO and ENSO. Journal of Climate, 22(13): 3786-3801.

Hoyt D V, Schatten K H, 1997. The Role of the Sun in Climate Change. New York: Oxford University Press.

Huang J, Zhang X, Zhang Q et al., 2017. Recently amplified arctic warming has contributed to a continual global warming trend. Nature Climate Change, 7(12): 875-879.

IPCC. Climate Change 2013: The Physical Science Basis, 2013. Contribution to Working Group I to the Fifth Assessment Report of the Intergovernmental Panel on Climate Change. Cambridge, United Kingdom and New York, USA: Cambridge University Press.

Jevrejeva S, Moore J C, Grinsted A, 2010. How will sea level respond to changes in natural and anthropogenic forcings by 2100? Geophysical Research Letters, 37: L07703. doi: 10.1029/2010GL042947.

Jones P D, Hulme M, 1996. Calculating regional climatic time series for temperature and precipitation: Methods and illustrations. International Journal of Climatology, 16(4): 361-377.

Jones P D, Lister D H, Osborn T J et al., 2012. Hemispheric and large-scale land-surface air temperature variations: An extensive revision and an update to 2010. Journal of Geophysical Research Atmospheres, 117: D05127. doi: 10.1029/2011JD017139.

Karl T R, Arguez A, Huang B et al., 2015. Possible artifacts of data biases in the recent global surface warming hiatus. Science, 348(6242): 1469-1472.

Kerr R A, 2009. What happened to global warming? Scientists say just wait a bit. Science, 326(5949): 28-29.

Knight J, Kenneby J, Folland C et al., 2009. Do global temperature trends over the last decade falsify climate predictions? Bulletin of the American Meteorological Society, 90(8): 22-23.

Kosaka Y, Xie S P, 2013. Recent global-warming hiatus tied to equatorial Pacific surface cooling. Nature, 501(7467): 403-407.

Lean J L, 2010. Cycles and trends in solar irradiance and climate. Wiley Interdisciplinary Reviews: Climate change, 1(1): 111-122.

Li J, Sun C, Jin F, 2013. NAO implicated as a predictor of Northern Hemisphere mean temperature multidecadal variability. Geophysical Research Letters, 40(20): 5497-5502.

Lin X P, Xu L X, Li J P et al., 2016. Research on the global warming hiatus. Advances in Earth Science, 31(10): 995-1000. (in Chinese)

Liu Chao, 2016. Study on influence of the PDO on sea level rise in the Pacific [D]. Qingdao: University of Chinese Academy of Sciences. (in Chinese)

Medhaug I, Stolpe M B, Fischer E M et al., 2017. Reconciling controversies about the 'global warming hiatus'. Nature, 545(7652): 41-47.

Meehl G A, Arblaster J M, Fasullo J T et al., 2011. Model-based evidence of deep-ocean heat uptake during surface-temperature hiatus periods. Nature Climate Change, 1(7): 360-364.

Qin D H, 2014. Climate change science and sustainable development. Progress in Geography, 33(7): 874-883. (in Chinese)

Rathod M, Gupta M, Shrivastava A K, 2017. Long-term variation of solar flare indices in relation to sunspot numbers from Solar Cycle 20 to 24. Journal of Pure Applied and Industrial Physics, 7(9): 339-347.

Roberts C D, Palmer M D, McNeall D et al., 2015. Quantifying the likelihood of a continued hiatus in global warming. Nature Climate Change, 5(4): 337-342.

Schmidt G A, Shindell D T, Tsigaridis K, 2014. Reconciling warming trends. Nature Geoscience, 7(3): 158-160.

Schneider N, Cornuelle B D, 2005. The forcing of the Pacific Decadal Oscillation. Journal of Climate, 18(21): 4355-4373.

Seager R, Kushnir Y, Nakamura J et al., 2010. Northern Hemisphere winter snow anomalies: ENSO, NAO and the 
winter of 2009/10. Geophysical Research Letters, 37: L14703. doi: 10.1029/2010GL043830.

Su J Z, Wen M, Ding Y H et al., 2016. Hiatus of global warming: A review. Chinese Journal of Atmospheric Sciences, 40(6): 1143-1153. (in Chinese)

Trenberth K E, Fasullo J T, Branstator G et al., 2014. Seasonal aspects of the recent pause in surface warming. Nature Climate Change, 4(10): 911-916.

Vinnikov K Y, Groisman P Y, Lugina K M, 1990. Empirical data on contemporary global climate changes (temperature and precipitation). Journal of Climate, 3(6): 662-677.

Wang S W, Luo Y, Zhao Z C et al., 2014. Pause for thought. Advances in Climate Change Research, 10(4): 303-306. (in Chinese)

Wen M, Yang S, Kumar A et al., 2009. An analysis of the large-scale climate anomalies associated with the snowstorms affecting China in January 2008. Monthly Weather Review, 137(3): 1111-1131.

Yan X H, Boyer T, Trenberth K et al., 2016. The global warming hiatus: Slowdown or redistribution? Earth's Future, 4(11): 472-482.

Yao S L, Huang G, Wu R G et al., 2016. The global warming hiatus: A natural product of interactions of a secular warming trend and a multi-decadal oscillation. Theoretical and Applied Climatology, 123(1/2): 349-360.

Zhang Z Y, Gong D Y, Guo D et al., 2008. Anomalous winter temperature and precipitation events in southern China. Acta Geographica Sinica, 63(9): 899-912. (in Chinese)

Zhao L, Ding R, Moore J C, 2016. The High Mountain Asia glacier contribution to sea-level rise from 2000 to 2050. Annals of Glaciology, 57(71): 223-231.

Zhao S Q, 1983. A new scheme for comprehensive physical regionalization in China. Acta Geographica Sinica, 38(1): 1-10. (in Chinese)

Zhao Z C, Luo Y, Huang J B, 2016. Debate on global warming "hiatus". Advances in Climate Change Research, 12(6): 571-574. (in Chinese) 